\title{
THE EFFECT OF THE COUNTRY OF ORIGIN ON THE CONSUMER, FROM THE PLACEBO EFFECT PERSPECTIVE
}

\author{
Muresan Lavinia PhD Candidate \\ West University of Timisoara \\ E-mail: 1.m.lavinia@gmail.com
}

(Received April 2015; accepted June 2015)

\begin{abstract}
Although it is mostly used in Medicine, the placebo effect has been exploited in Marketing as well, in recent years. In Medicine, the placebo effect is defined as the improving state of a patient as a result of administering a simulated treatment, without any therapeutic healing effect. The current paper presents the results obtained in the studies that tested the placebo effect in marketing, and the conclusions of an experiment in which the possibility of producing the placebo effect on the consumer when the country of origin of an identical product differs was tested.
\end{abstract}

Key words: Placebo effect, brand, price, country of origin

J.E.L. Classification: M310; M370

\section{Introduction}

The country of origin, globally recognized by the "made in" label, represents the country in which the product is created/produced. However, consumers make numerous connections between the product and its country of origin, connections related to the quality of the product and its performance. The current paper presents a review of the studies that have been made about the placebo effect of brands and prices on the consumer, and extends the research to another factor that can manifest itself as placebo, namely the country of origin of the product.

\section{The Country of Origin}

The specialized literature shows that one of the factors which influence the consumers' perception related to the value and quality of products and brands is the country of origin of those products and brands. The country of origin is one of the main factors that determine the consumer's knowledge about a certain type of product. Consumers differentiate between products coming from different countries, a phenomenon known as the country of origin effect. The country of origin effect is imbedded in the consumer's memory and it leads to the association of a certain quality to the products sold by brands with different origins. Consumers learn the product-country association in multiple ways: through direct experience of the product consumption, information acquired from advertising, information obtained from verbal interpersonal communication (word of mouth), information received from the popularization press. 
Consumers often use the information about a product's country of origin to evaluate the respective product. In Schooler's (1971) study it was found that there are significant differences in evaluating products that are identical in all aspects except for the country of origin on the "made in" label. This was one of the first studies carried out in order to determine the effect that the country of origin has on the product assessment.

Erickson et all (1984) determined that the country of origin can lead to the formation of perceptive prejudice, of stereotypes related to the products. According to their study, the authors concluded that efficient automobiles are associated with the Japanese origin, and quality automobiles are associated with the German origin. Based on this study, Johansson, Douglas and Nonaka (1985) confirm that the country of origin affects the consumer's attitude towards the product, favouring their perception of certain attributes, such as the fuel consumption or driving comfort. The authors also find that this favouring is stronger when the knowledge about the product is limited.

\section{The Placebo Effect}

The placebo effect is a high interest subject in the medical world, as well as in Psychology. The mechanism of the placebo effect gains more and more interest from researchers. Up to this point, there are two known models of manifestation of the placebo effect: the theory of expectation (or the expectative theory), and the theory of reflexive conditioning (Pavlov).

According to the theory of expectation, the placebo effect appears because there is a set of expectations related to the treatment that serves as a placebo, which generates a certain expected result, and this subsequently affects the performance of the treatment. On the other hand, the reflexive conditioning theory claims that the placebo effect is the conditional response to the administration of a treatment. The placebo effect represents the physiological and psychological effect that determines the improvement of a patient's health state as a result of a placebo being administered. As the medical anthropologist Daniel Moerman (2001) pointed out, the placebo effect is not caused by the placebo itself, but rather by the conviction, expectations and potential previous conditioning related to the placebo, namely the significance the patient gives to the substance or procedure that is being administered. The significance of the answer represents in his view the physiological and psychological effects of the significance in the treatment of the ailment. In this context, the results of the treatment can be influenced by stimuli such as language (what is said and how it is said), the procedures (what is done and what explanations are offered), the space in which the patient-doctor meeting takes place (clinic, hospital etc.), the way in which the information offered (verbally and 
Muresan, L., (2015)

The effect of the country of origin on the consumer, from the placebo effect perspective

non-verbally) is integrated in the personal history and the socio-cultural convictions of the patient.

\section{The Placebo Effect in Marketing}

In Marketing there are numerous factors that can behave as a placebo for consumers. For example, when a brand claims it has certain properties, even though it doesn't, those properties still change the consumer's perception of the product. Shiv, Cameron and Ariely (2005) demonstrate in their paper that the pricing and advertising messages of the products can alter the real effectiveness of the sold product, by influencing the expectations of the consumers. The more a person pays for a drink that is promoted as very effective in increasing mental accuracy, the more the performance enhancement effect will grow. However, this aspect is only observed when the person is being presented with the advertising message together with the price. On the other hand, when the lower price of the product is presented, the performance drops as well. This indicates that by repeated exposure, objects with a high price tend to be associated with high quality, and are consequently expected to produce more usefulness for the consumer.

Trying to see if the brand acts as a placebo on the consumer, Fitzsimons, Chartrand and Fitzsimons (2008) undergo a study to demonstrate that the exposure to a brand can provoke automated effects in the consumer's behavior when the consumer's wish is in accordance with the brand's characteristics.

When reviewing the specialized literature, no studies have been found so far to research the effect of the country of origin on the consumer's decision from the placebo effect perspective. Based on the research carried out related to the country of origin as an influencing factor in the consumer's decision, we want to verify the influence of this factor on the consumer from the placebo effect perspective.

The following hypotheses have been set forth and are to be verified in a future research study:

Hypothesis 1 Out of two identical products, the majority of users choose the one associated with a renowned country.

Hypothesis 2 Out of two identical products with "made in" labels stating different countries, the majority of users will be willing to pay more for the one produced in a renowned country.

Hypothesis 3 Out of two identical products, the majority of users will report higher quality for the one produced in a renowned country.

\section{Research Methodology}

In order to determine if the country of origin has a placebo effect on the consumer a combination of research methods have been used: a marketing experiment together with a descriptive research. 
The research was carried out through an experiment that included a product test and the completion of a questionnaire pre and post testing, on a sample of 15 females, aged 18 to 35, from urban areas, with average and above average income. The experiment was carried out by using two foundation creams from the Max Factor brand, identical in all aspects: shade, packaging, country of origin, country of acquisition. The original labels of the product were removed from the container in order to prevent them from influencing the users. The labels detailing the ingredients and the country of origin were replaced, keeping the information about the ingredients, but on one of the labels France was marked as the country of origin. The brand of the product wasn't mentioned either, to avoid brand influence on the respondents.

The reason for which we have chosen France as the country of origin is that this country is recognized worldwide as a cosmetics and perfume producer.

The respondents were questioned about the habits and frequency of foundation cream usage. Then they were asked to analyze the products that were handed out to them, and to try and identify the potential differences between them, as we wanted the different countries of origin to be observed by them, rather than for them to be communicated by the operators. After this, they were invited to test the products and then evaluate them through the posttest questionnaire.

The products were named Product A (Made in Ireland) and Product B (Made in France), but the respondents were allowed to test them in the order they chose, even multiple times, without any time limitation for the testing. The operator acted as an observer and assistant if necessary, and was trained on how to proceed in order to avoid influencing the respondent in any way.

\section{Research Results}

The hypotheses were verified through the analysis of the reactions obtained from the participants to the two products. It is also worth mentioning that $33 \%$ of the respondents observed that the products seem to be identical, maybe even the same product, but they assessed the products according to the instructions.

$60 \%$ of the respondents stated they use cosmetic make-up products on a daily basis, $20 \%$ of them using foundation cream a few times per week, while $20 \%$ only use it on weekends/special occasions (Table 1).

It is important to note that the products were tested by a high number of people who use this type of product on a daily basis, which leads us to believe that there is a product usage experience and certain expectations.

The first two hypotheses were verified with the help of the binominal test. We considered that $65 \%$ (the majority) of the respondents will opt for the purchase of 
Muresan, L., (2015)

The effect of the country of origin on the consumer, from the placebo effect perspective

the product made in France and that $65 \%$ (the majority) will also be willing to pay more for the same product made in France.

Table 1. Frequency of cosmetic products usage

\begin{tabular}{|l|c|c|c|c|}
\hline & Frequency & Percentage & $\begin{array}{c}\text { Valid } \\
\text { percentage }\end{array}$ & $\begin{array}{c}\text { Cumulated } \\
\text { percentage }\end{array}$ \\
\hline $\begin{array}{l}\text { Sometimes, during the week / } \\
\text { on special occasions }\end{array}$ & 3 & 20.0 & 20.0 & 20.0 \\
\hline During the weekend & 3 & 20.0 & 20.0 & 40.0 \\
\hline Daily & 9 & 60.0 & 60.0 & 100.0 \\
\hline Total & 15 & 100.0 & 100.0 & \\
\hline
\end{tabular}

Source: author's research

As it can be observed, the distribution within the sample isn't different from the theoretical distribution, so both null hypotheses according to which there aren't significant statistical differences between the tested values (for the first hypothesis, the buying preference variable, and for the second hypothesis the buying intention in relation to pricing variable) are validated. This is supported by the significance level of 0.62 and 0.564 respectively, both greater than 0.01 . Thus, both hypotheses - "Out of two identical products, the majority of users choose the one associated with a renowned country" and "Out of two identical products with "made in" labels stating different countries, most users will be willing to pay more for the one produced in a renowned country" - are valid (Table 2 and Table 3 ).

Table 2. The Binomial Test - Hypothesis 1

\begin{tabular}{|l|l|c|c|c|c|}
\hline $\begin{array}{l}\text { Following the testing, } \\
\text { which one of the two } \\
\text { products would you buy? }\end{array}$ & Category & $\mathrm{N}$ & Observed Prop. & Test Prop. & $\begin{array}{c}\text { Exact Sig. } \\
\text { (2-tailed) }\end{array}$ \\
\hline Group 1 & Product B & 13 & .87 & .65 & .062 \\
\hline Group 2 & Product A & 2 & .13 & & \\
\hline Total & & 15 & 1.00 & & \\
\hline
\end{tabular}

Source: author's research

Table 3. Binomial Test - Hypothesis 2

\begin{tabular}{|l|l|l|l|l|l|}
\hline $\begin{array}{l}\text { Following the testing, which one of the two } \\
\text { products would you buy, considering that } \\
\text { product B (made in France) is 10\% more } \\
\text { expensive than product A (made in Ireland)? }\end{array}$ & Category & $\mathrm{N}$ & $\begin{array}{l}\text { Observed } \\
\text { Prop. }\end{array}$ & $\begin{array}{l}\text { Test } \\
\text { Prop. }\end{array}$ & $\begin{array}{l}\text { Exact Sig. } \\
\text { (2-tailed) }\end{array}$ \\
\hline Group 1 & Product B & 10 & .67 & .65 & .564 \\
\hline Group 2 & Product A & 5 & .33 & & \\
\hline Total & & 15 & 1.00 & & \\
\hline
\end{tabular}

Source: author's research 
In order to verify the third hypothesis, "Out of two identical products, the majority of users will report a higher quality for the one produced in a renowned country", test $\mathrm{T}$ pairs for linked samples was used. The results demonstrate that the difference between the average rating of product $\mathrm{A}$ is different to the average rating of product B. This is also sustained by the calculated value of $\mathrm{T}-3.389$, which is smaller than the critical value of $\mathrm{T} 0.004$, so the hypothesis stating that "Out of two identical products, the majority of users will report a higher quality for the one produced in a renowned country" is validated (Table 4.1. and Table 4.2).

Table 4.1. Paired Samples Test

\begin{tabular}{|c|c|c|c|}
\hline \multicolumn{3}{|l|}{ Pair 1} & $\begin{array}{l}\text { Quality rating product A - } \\
\text { Quality rating product B }\end{array}$ \\
\hline \multirow{5}{*}{$\begin{array}{l}\text { Paired } \\
\text { Differences }\end{array}$} & \multicolumn{2}{|l|}{ Mean } & $-0,86667$ \\
\hline & \multicolumn{2}{|l|}{ Std. Deviation } & 0,99043 \\
\hline & \multicolumn{2}{|l|}{ Std. Error Mean } & 0,25573 \\
\hline & \multirow{2}{*}{$\begin{array}{l}95 \% \text { Confidence Interval } \\
\text { of the Difference }\end{array}$} & Lower & $-1,41515$ \\
\hline & & Upper & $-0,31818$ \\
\hline \multicolumn{3}{|l|}{$\mathrm{t}$} & $-3,389$ \\
\hline \multicolumn{3}{|l|}{$\mathrm{df}$} & 14 \\
\hline \multicolumn{3}{|c|}{ Sig. (2-tailed) } & 0,004 \\
\hline
\end{tabular}

Source: author's research

Table 4.2 Paired Samples Statistics

\begin{tabular}{|c|c|c|c|c|}
\hline Pair 1 & Mean & $\mathrm{N}$ & Std. Deviation & Std. Error Mean \\
\hline Quality rating product A & 3.8667 & 15 & 1.06010 & .27372 \\
\hline Quality rating product B & 4.7333 & 15 & .45774 & .11819 \\
\hline
\end{tabular}

Source: author's research

\section{Conclusions}

The research conducted indicates that people tend to be influenced in choosing a product and in assessing it by the country of origin that appears on the product's packaging. The laboratory study points out that the country of origin can act as a placebo for the users. It is observed that the placebo effect manifests itself through "expectation" (the expectative theory): they expect the product made in France to be better from the quality point of view; they are willing to buy it even when the price differs.

Due to the fact that the literature related to the placebo effect in marketing is very young, carrying out more experiments and testing more hypothesis are required. Some limitations to the current experiment are: the low number of respondents, that doesn't allow a generalization of the findings, the unrepresentative sample 
Muresan, L., (2015)

The effect of the country of origin on the consumer, from the placebo effect perspective

compared to the entire population, as well as the lack of A/B testing with products truly produced in different countries.

Acknowledgement

This work was co-financed from the European Social Fund through Sectoral Operational Programme Human Resources Development 2007-2013, project number POSDRU/159/1.5/S/134197 „Performance and excellence in doctoral and postdoctoral research in Romanian economics science domain"

\section{Bibliography:}

1. Amar, M., Ariely, D. Bar-Hillel, M., Cameron Z. si Ofir, C. (2011). Brand names act like marketing placebos. The Hebrew University of Jerusalem - Center for the Study of Rationality, discussion paper 566 (February), 1-7, Jerusalem, Israel 2. Benedetti, F., Mayberg, H. S., Wager, T. D., Sohler, C. S., \&Zubieta, J. K. (2005). Neurobiological mechanisms of the placebo effect. The Journal of Neuroscience, 25, 10390-10402.

3. Erickson, G. M., Johansson, J. K., \& Chao, P. (1984). Image variables in multiattribute product evaluations; Country-of-origin effects. Journal of Consumer Research, 11, 694-699.

4. Fitzsimons, G.J., Chartrand, T.L., Fitzsimons, G.M., (2008) Automatic Effects of Brand Exposure on Motivated Behaviour: How Apple Makes You "Think Different". Journal of Consumer Research Inc., vol.35, 21-35, University of Chicago Press, Chicago

5. Irmak, C., Block, L.G., Fitsimons, G.J., (2005) The Placebo Effect in Marketing: Sometimes You Just Have to Want it to Work. Journal of Marketing, vol. XLII (November), 406-409, The American Marketing Association, Chicago

6. Johansson, J.K., Douglas, S.P., Ikujiro Non-aka (1985), "Assessing the Impact of County of Origin on Product Evaluations: A New Methodological Per-spective," Journal ofMarketing Research, 22 (Novem- ber), 388-396.

7. Moerman, D., (2001) Explanatory Mechanisms For Placebo Effects: Cultural Influences and The Meaning Response, The Science of the Placebo: Toward an Interdisciplinary Research Agenda, London: BMJ Publishing 77-107

8. Schooler, R.D. (1965), "Product bias in the Central American common market', Journal of Marketing Research, Vol. 2 No. 4, pp. 394-7.

9. Schooler, R.D. (1971), "Bias phenomena attendant to the marketing of foreign goods in the US", Journal of International Business Studies, Vol. 2 No. 1, pp. 7180.

10. Shiv, Baba, Carmon, Ziv si Ariely, Dan (2005). Ruminating About Placebo Effects of Marketing Actions. Journal of Marketing Research, vol. XLII (November), 410-414, The American Marketing Association, Chicago 